Copyright (c) 2015 by Academic Publishing House Researcher

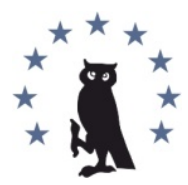

Published in the Russian Federation

European Researcher

Has been issued since 2010 .

ISSN 2219-8229

E-ISSN 2224-0136

Vol. 93, Is. 4, pp. 260-269, 2015

DOI: $10.13187 /$ er.2015.93.260

www.erjournal.ru

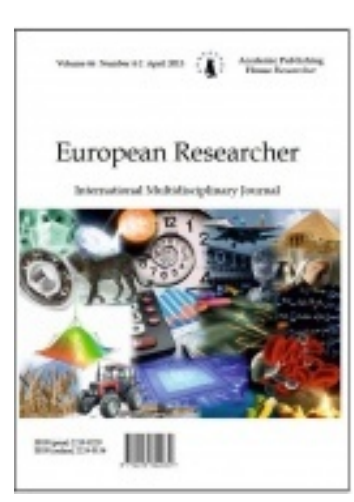

Economic sciences

Экономические науки

UDC 33

\title{
Decision Making Based On Management Information System and Decision Support System
}

\author{
${ }^{1}$ Şükrü Ada \\ 2 Mohsen Ghaffarzadeh
}

1-2 Ataturk University, Turkey

${ }^{1}$ Associate Professor

E-mail: sukruada@atauni.edu

$2 \mathrm{PhD}$ student

E-mail: ghaffarzadeh.1361@gnail.co

\begin{abstract}
Information has become an essential resource for managing modern organizations. This is so because today's business environment is volatile, dynamic, turbulent and necessitates the burgeoning demand for accurate, relevant, complete, timely and economical information needed to drive the decision-making process in order to accentuate organizational abilities to manage opportunities and threat. MIS work on online mode with an average processing speed. Generally, it is used by low level management. Decision support system are powerful tool that assist corporate executives, administrators and other senior officials in making decision regarding the problem. Management Information Systems is a useful tool that provided organized and summarized information in a proper time to decision makers and enable making accurate decision for managers in organizations. This paper will discuss the concept, characteristics, types of MIS, the MIS model, and in particular it will highlight the impact and role of MIS on decision making.
\end{abstract}

Keywords: management information systems; decision support systems; decision-making.

\section{Introduction}

Number of authors has discussed the role of information system in decision making, Kostetsky was one of the first authors who wrote about the relationship between information systems, system analyst and decision making in 1966. Management information system provides knowledge about the relative position of the organization and basic forces at work. It provides the right information needed in decision making process and help the organizations control, planning and operational functions to be carried out effectively (Leonard, 2008). Furthermore, Ajayi I.A. and Omirin, Fadekem investigated the use of management information systems in decision-making on long-term planning, short-term planning and budgeting in the South-West Nigerian 
Universities. A stratified random sampling technique was used to collect data and conclude that that there was a significant difference in the use of MIS for decision making on budgeting between Federal and State universities in favor of the Federal universities. The authors recommend that the MIS units should be adequately financed and maintained to ensure a free flow of information and adequate use of MIS in decision-making on short-term and long-term planning as well as budgeting. Ali Safari and Asefeh Asemi have discussed two main information systems, namely, MIS and DSS, its characteristics, relations, and connections of each concept to decision-making process. Srinivas Nowduri has the same consumption about the relationship between MIS and decision making. Decision making process and its impact on top level management in a business organization was explained also with an emphasis on automated decision making. The study found that the dynamic nature of MIS makes it difficult for some organizations to keep up with the principles, strategies, propositions or even ideas. Barry Chris, provide added a new conceptual framework for decision making and information systems development, same as another authors who analyzed the role of MIS in decision making. A framework was developed, combining an analysis of decision making within the systems development life cycle, key models of decisionmaking and the actors involved in the process of systems development. Barry Chris concludes that a deeper understanding of differing viewpoints on systems development held by actors and other phenomena can be illustrated with the framework. George Huber also draws a theory of effects of advanced information technologies on organizational design, intelligent and decision making, the theory studied the effects that computer- assisted communication and decision aiding technologies have on organizational design and decision making. Humber focuses on technology that affects the quality and timelines of decision making from one side and from the other side has prompted changes in organizational design. On the other hand Felix Alvarado in his study "Complementary uses of Information Systems in Decision Making, Planning and Democracy: An Example in the Education Sector" describes the ongoing implementation of web intelligence tools in public education and other policy sectors in Guatemala. Software tools were developed for use in business was adopted for planning and decision making in public institutions. The study summarizes the salient aspects of the experience so far of implementing and expanding what has been called the "Platform for Integrated Social Information," It discusses the issues this Platform raises as a resource for improved public decision making, policy analysis and especially, as a promising but challenging tool for democracy in the education sector. However, the world health organization has introduced a report by who study group it was about the role of research and information systems in decision making for the development of human resource for health, the study identified a number of problems and noted causes of these problems such as inefficient data definition and, lack of relevant information and poor coordination of available information on the other hand the study identified a positive factors that prompt decision making such as problem awareness and easy availability of presented information. The study group emphasized that strengthening decision making in the development of human resource of health, by linking information and research to decision making and prompting relevant information requires a coordinated approach.

\section{Information System}

Information system are constantly changing and evolving as technology continue to grow .Basically we have many types of information system like management information system, decision support System, transaction processing system, expert system. But we discuss management information system and decision support system. In Management information system these system assist lower level management in problem solving and making decision (Manian, 2011). They use the result of transaction processing and some other information also. It is a set of information processing functions. It should handle queries as quilt as they arrive. An important element of management information system is database. In decision support system, they assist higher management to make long term decisions. These types of systems handle unstructured or semi structured decision .A decision is considered unstructured if there are no clear procedure for making the decision and if not all the factor to be considered in the decision can be readily identified in advance. The decision support system these are not of recurring nature. Some recur infrequently or occur only once. A decision support system must very flexible. The user should be able to produce customized reports by giving particular data and format specific to 
particular situations. There are different views in determining the types of information systems and their classifications. But in most categories, with titles such as: (Laudon and Laudon, 2009)

\section{Transaction Processing System (TPS)}

This is also referred to as data processing system. It performs the essential role of collecting and processing the daily transactions of the organization. They serve at operational levels of the organization. Examples of transactions include purchase payroll, reservation, invoices, payments, shipping, registrations, orders and sales.

\section{Expert System (Specialist) (ES)}

This is an extension of the decision support system. It is a programmed decision-making information system that captures and reproduces the knowledge and expertise of experts and then simulates the thinking or actions of that expert to help users with less expertise. These applications are implemented with Artificial Intelligence (AI) technology. Artificial intelligence is a computerbased technology that has the ability to behave like humans, learn languages and emulate human expertise and decision-making.

\section{Office Automation System (OAS)}

This system supports a wide range of business activities. Office systems are applications designed to improve workflow and communicate among workers regardless of their physical locations. Typical office system handles and manages document (through word processing, desktop publishing, document imaging and digital filings), scheduling (through electronic calendars) and communication (through electronic mail, voice mail and video conferencing).

\section{Personal and Work Group Information Systems (WGSS)}

Personal information system is the system designed to meet the needs of a single user while work group system is designed to meet the needs of a workgroup and to increase the productivity of the group.

\section{Management Information System (MIS)}

The Management Information System (MIS) is a concept of the last decade or two. It has been understood and described in a number ways. It is also known as the Information System, the Information and Decision System, the Computer- based information System (Davis \& Geist, 2004). Definition of Management Information Systems: The MIS is defined as a system which provides information support for decision making in the organization (Barton \& Parolin, 2005). The MIS is defined as an integrated system of man and machine for providing the information to support the operations, the management and the decision making function in the organization (Bendoly, 2008). The MIS is defined as a system based on the database of the organization evolved for the purpose of providing information to the people in the organization. The MIS is defined as a Computer based Information System (Bresfelean, 2009).

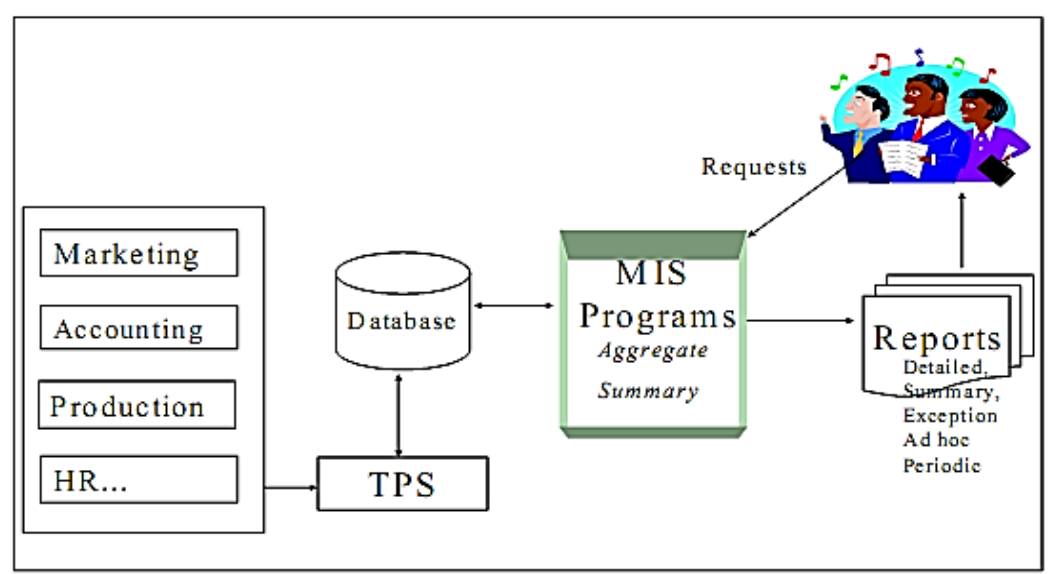

Figure 1. Simple View of MIS (Kumar, 2006, 45) 


\section{Decision Support System (DSS)}

Decision-making is an essential component of organizational life. Decision makers receive and analysis information using many different media, including traditional print, group and interpersonal information exchanges and computer-based tools Decision support systems (DSS) is a generic concept that describes information systems that provide analytical modelling and information to support semi-structured and unstructured organizational decision making. Common characteristics of DSS include:

- Problem structure, used in semi-structured and unstructured decision context

- Intended to support and augment decision makers not replace them

- Supports most phases of decision-making process

- Uses underlying data and model

- Interactive: DSS is designed to be an interactive decision aid

A decision support system (DSS) is an integrated set of computer tools allowing a decision maker to interact directly with computer to retrieve information useful in making semi structured and unstructured decisions (Power, 2002. Ezine, 2010. J ames, 1998). The Decision support system are able to help groups to make the decision .It should not be responsible for individual decision making. The Decision support system is easy to use. A user should not be required to be computer operator to generate reports. It should be convenient for the user to use DSS (Singh \& Sharma, 2012).

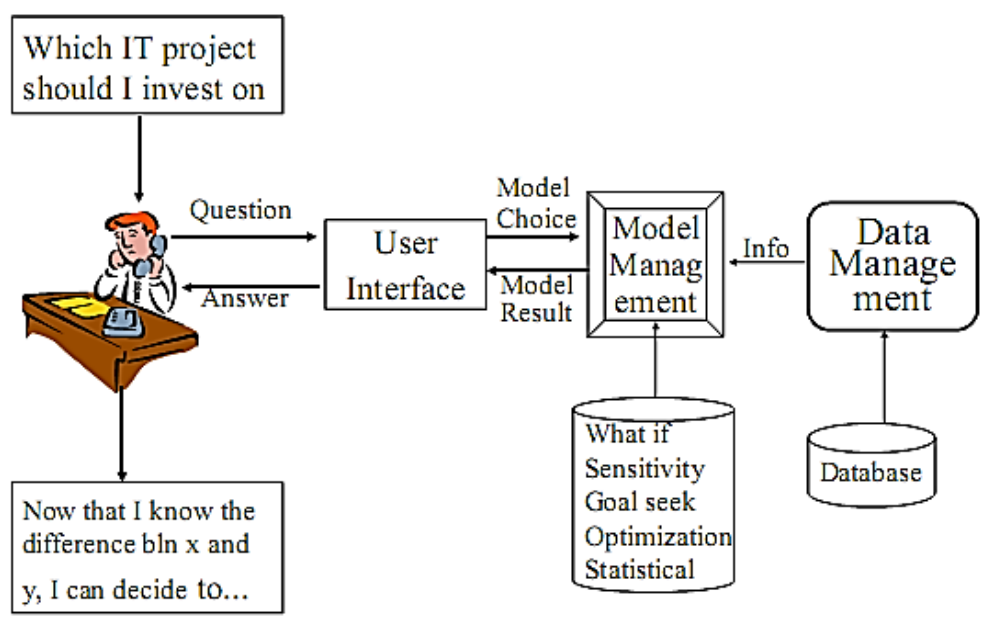

Figure 2. A Simple View of DSS ((Kumar, 2006, 75)

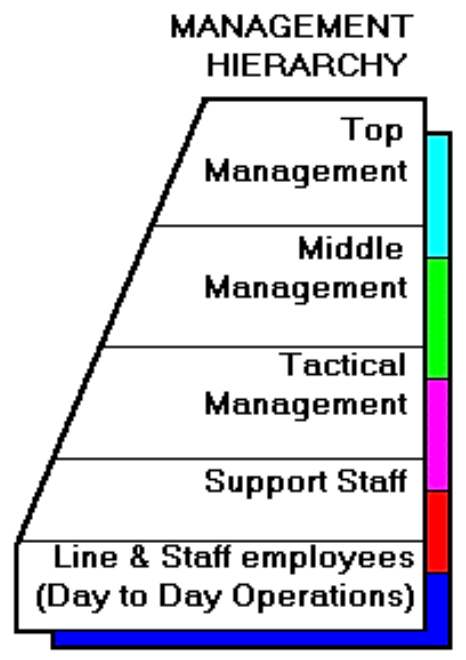

INFORMATION SYSTEM HIERARCHY

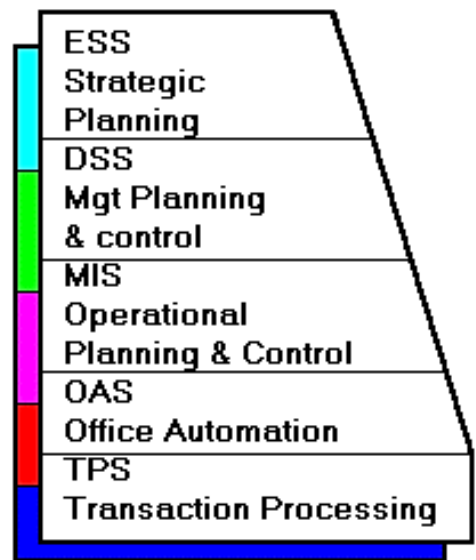

Figure 3. Types of Information systems and organizational hierarchy (Gabriel, 2012, 89) 


\section{Types of Decision Support System}

There are a number of decision support systems. These can be categorized into five types: communications driven DSS, data driven DSS, document driven DSS, knowledge driven DSS and model driven DSS. A communication driven DSS supports more than one person working on a shared task. Many collaborators work together to come up with a series of decision to set in motion a solution or strategy. Most communications driven DSSs are targeted at internal teams, including partners. The most commons technology used to deploy the DSS is a web or a client server. In general, groupware, bulletin boards, audio and video conferencing are the primary technologies for communication driven decision support. Data driven DSS model puts its emphasis on collected data that is then manipulated to fit the decision maker's needs. This data can be internal, external and in a variety of formats. This model emphasizes access to and manipulation of a time series of internal company data and sometimes external and real time data. Simple file systems accessed by query and retrieval tools provide the most elementary level of functionality. Most data driven DSSs are targeted at managers, staff and also product / service suppliers. It is used to query a database or data warehouse to seek specific answers for specific purposes. It is deployed via a main frame system, client server link or via web. Document driven DSSs are more common, targeted at a broad base of user groups. The purpose of such a decision support system is to search web pages and find documents on a specific set of keywords or search terms. This model uses computer storage and processing technologies to provide document retrieval and analysis. A document driven DSS model uses documents in a variety of data type such as text documents, spreadsheets and database records to come up with decisions and manipulate the information to refine strategies. The usual technology used to set up such decision support systems are via web or a client / server system. Knowledge driven DSSs are a catch-all category covering a broad range of systems covering users within the organization setting it up, but may also include others interacting with the organization. It is essentially used to provide management advice or to choose products or services. Knowledge-driven DSS can suggest or recommend actions to managers. These DSS are person-computer systems with specialized problem-solving expertise. The expertise consists of knowledge about a particular domain, understanding of problems within that domain, and skill at solving some of these problems. The typical deployment technology used to set up such systems could be client / server systems, the web, or software running on stand-alone PCs. Model driven DSSs are complex systems that help analyses decisions or choose between different options. A model driven DSS emphasizes access to and manipulation of financial, optimization and / or simulation models. Simple quantitative models provide the most elementary level of functionality. Model-driven DSS use limited data and parameters provided by decision makers to aid decision makers in analyzing a situation, but in general large data bases are not needed for model-driven DSS. These are used by managers and staff members of a business, or people who interact with the organization, for a number of purposes depending on how the model is set up. These DSSs can be deployed via software / hardware in standalone PCs, client/ server systems or the web (Holsapple \&Whinston, 2006).

\section{Difference of MIS and DSS}

MIS and DSS are two abbreviations that are often heard in the field of Business Management. They differ in a few aspects. It is important to know that MIS stands for Management Information Systems whereas DSS stands for Decision Support Systems. It is interesting to note that MIS is a type of link that assists in the communication between managers of various disciplines in a business firm or an organization. On the whole it plays a very important role in building up communication among the corporate people. DSS on the other hand is an improvement of the concept of MIS. It is true that both of them differ in terms of their focus. DSS focuses more on leadership. It is all about senior management in a firm providing innovative vision. On the other hand MIS focuses more on the information gathered and the information that has poured from different quarters. Experts on managerial behavior say that DSS focuses more on decision making. MIS on the other hand focuses more on planning the report of various topics concerned with the organization that would assist the managers to take vital decisions pertaining to the functioning of the organization. One of the finest differences between MIS and DSS is that MIS focuses on operational efficiency whereas DSS focuses more on making effective decision or in other words helping the company to do the right thing. Flow of information is from both sides, up and down in the case of MIS. 
On the other flow of information is only upward in the case of DSS. In the case of DSS the report can be flexible whereas in the case of MIS the report is usually not flexible. MIS is characterized by an input of large volume of data, an output of summary reports and process characterized by a simple model. On the other hand DSS is featured by an input of low volume of data, an output of decision analysis and a process characterized by interactive model. Experts would also say that MIS is a primary level of decision making whereas DSS is the ultimate and the main part of the decision. This is one of the most talked about different between the two. As a matter of fact MIS is all about theory whereas DSS is all about practice and analysis. An organization should employ both the systems effectively (Pride and Ferrell, 2006).

\section{Decision-Making}

Decision-making is the process by which organizational members choose specific course of action in response to threats and opportunities (George and J ones, 1996: 428). Good decision result in courses of actions that help an individual, group or organization to be effective, the opposite is its reverse. Every organization grows, prospers or fails as a result of decisions made by

It is members; and decision according to Daft (2001: 399) can be risky and uncertain without any success. Simon (1984), a leading authority in management decision- making considers that decision making comprises four principal phases:

- Intelligence- searching the environment for conditions calling for decision making.

- Design- inventing, developing and analyzing possible courses of actions. This involves processes to understand the problem, to generate solutions and testing of solutions for feasibility.

- Choice- selecting an alternative or course of action from those variables.

- Review - assessing past choices. This model was later incorporated by George Huber into an expanded model of the entire problem-solving process (see figure 4).

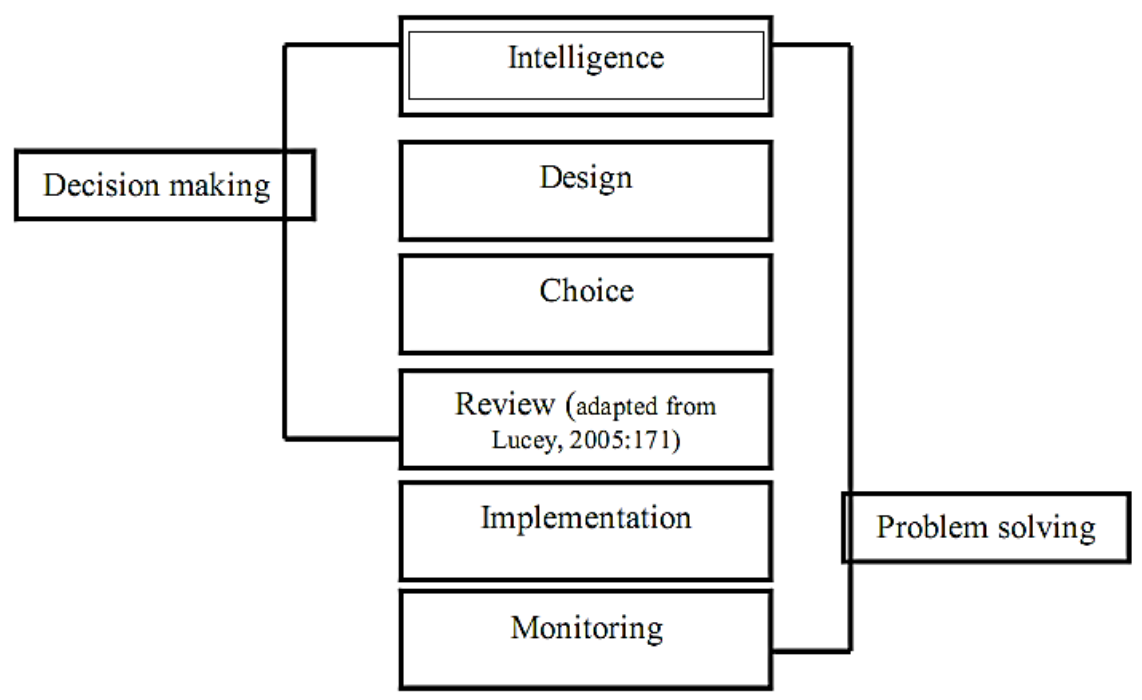

Figure 4. Process of Decision-Making (Renolds, 2003, ppt 65)

\section{Types of Decisions}

A simple view of decision making is that it is a problem of choice among several alternatives. A somewhat more sophisticated view includes the process of constructing the alternatives (i.e., give a problem statement, developing a list of choice options). A complete picture includes a search for opportunities for decisions (i.e., discovering that there is a decision to be made). A manager of company may face a choice in which the options are clear (e.g., the choice of a supplier from among a existing suppliers). She may also face a problem for which she designs creative decision options (e.g., how to market a new product so that the ports are maximized). Finally, she may work in a less reactive fashion and view decision problems as opportunities that have to be discovered by studying the operations of her company and its surrounding environment (e.g., how can she make the production process more evident). There is much anecdotal and some empirical evidence that 
structuring decision problems and identifying creative decision alternatives determine the ultimate quality of decisions. Decision support systems aim mainly at this broadest type of decision making and in addition to supporting choice, they aid in modeling and analyzing systems (such as complete organizations), identifying decision opportunities, and structuring decision problems. Simon (1984) classified decisions into two broad categories according to the extent that the process of decision-making can be pre-planned:

- Programmed Decision: these are decisions made using standard rules, procedures or quantitative methods. To make a programmed decision, the decision maker uses a performance program, a standard sequence of behavior that organizational members follow routinely whenever they encounter a particular type of problem or opportunity (George and J ones :429). For example, inventory control decisions, machine loading decisions, scheduling, etcetera.

- Non-programmed Decisions: this type if decision deals with unusual or exceptional situations. They are decisions made in response to novel problems and opportunities. This type of decision according to Lucey (2005: 171), is associated with high degree of uncertainty, cannot be delegated to low levels, may involve things, but always involves people. Examples: merger, acquisitions, launching of new product, personnel appointments, etcetera. Whether decision is of the programmed or non-programmed type, it depends hugely on inputs from management information systems.

Having good decision choices guarantees viable decision in organizations (Vital and Shivraj, 2008; and J awadekar, 2006). Rhodes (2010) avers that MIS gives managers quick access to information. This can include interaction with other decision support systems, information inquiries, cross referencing of external information and potential data mining techniques. At other instances, MIS also is said to have revolutionized decision-making process through automated systems, through such systems, managers no longer rely on 24 hour service from workers, instead, machines are to be programmed to do things, such as routine decisions, in place of humans (J arboe, 2005). In his thinking, Adebayo (2007) stressed that MIS provides information that is needed for better decision on issues affecting organizations regarding humans and material resources. Lucey (2005:179) argued MIS supplies information explores alternatives and provides support where the manager takes the decision or the MIS takes the decision itself, especially the routine operational decisions.

\section{Decision and MIS}

Development of information and communication technologies as change structures of societies, it also affected task of manager's making decision. Many organizations prepare them self for effective and efficient use of new information and communications technologies. Information and communication technology has two benefits for organization. First, it enables organizations and managers to easily acquire data. This will cause further support the decision making process. Second, the use of information and communication technology enables organizations to have better operate in a global competitive environment and make effective decision making. Information and communication technology improve the quality of decision making that is crucial factor for organization. Cause dramatic changes in levels of the organization, including organizational leadership and strategy, and even members behavior. The information and communication technology has become an essential component in the process of decision making in organization and managers at all levels increasingly get help from information and communication technologies (Feizi \& Moghadassi, 2012). No doubt modern information and communication technologies provide the field of information management system. Information and communication technology enables collect, analyze and evaluate data and transferring them from one point to another and cause instant access to information, Reduce costs, Produce better, Carefully, Coordination, Leading time, improved control and will lead to better services. No doubt, management has been a necessity for human since past, If you consider different management activities can be clearly seen that the essence of all the management activities is making decision. Decision making is an integral component of management. In each task, the management is so smart. In determine organization's policies, development objectives. Organization design, Choice, Assessment and management practices in all forms, Decision-making are one of the main fundamental pillars. In a simple definition, decision making is choose a way between different paths (Alvani, 2012). 


\section{MIS and Decision Making Process}

According to Obi (2003), MIS is useful in the area of decision making as it can monitor by itself disturbances in a system, determine a course of action and take action to get the system in control. It is also relevant in nonprogrammer decisions as it provides support by supplying information for the search, the analysis, the evaluation and the choice and implementation process of decision making. Adebayo (2007) stressed the need for MIS in decision making as it provides information that is needed for better decision making on the issues affecting the organization regarding human and material resources(Reddy,2009).

MIS is an organization - wide effort to provide decision making process information. The system is a formal commitment by executive to make the computer available to all managers. MIS sets the stage for accomplishments in the other area, which is DSS, the virtual office and knowledge based systems. The main idea behind MIS is to keep a continuous supply of information flowing to the management. Afterwards, by data and information gathered from MIS, decisions are made (Asemi \& Safari, 2011).

MIS may be viewed as a mean for transformation of data, which are used as information in decision-making processes. Figure 1 shows this understanding about information as data processed for a definite purpose (Lucey, 1997).

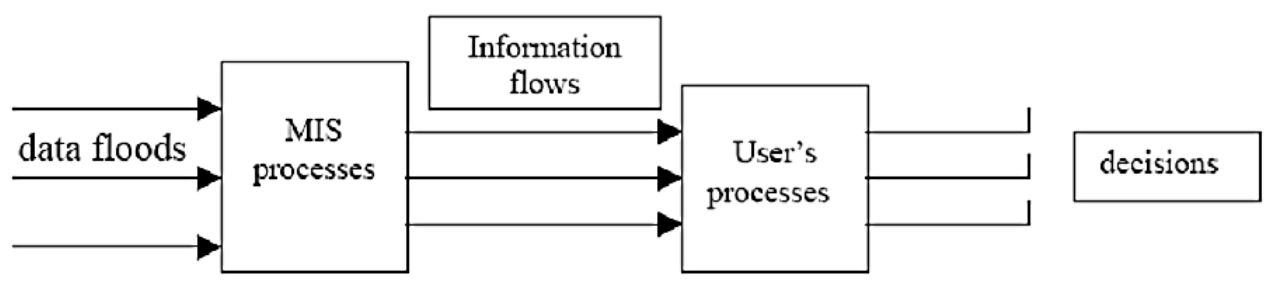

Figure 5. MIS and decision making process (Ajayi, 2007, 97)

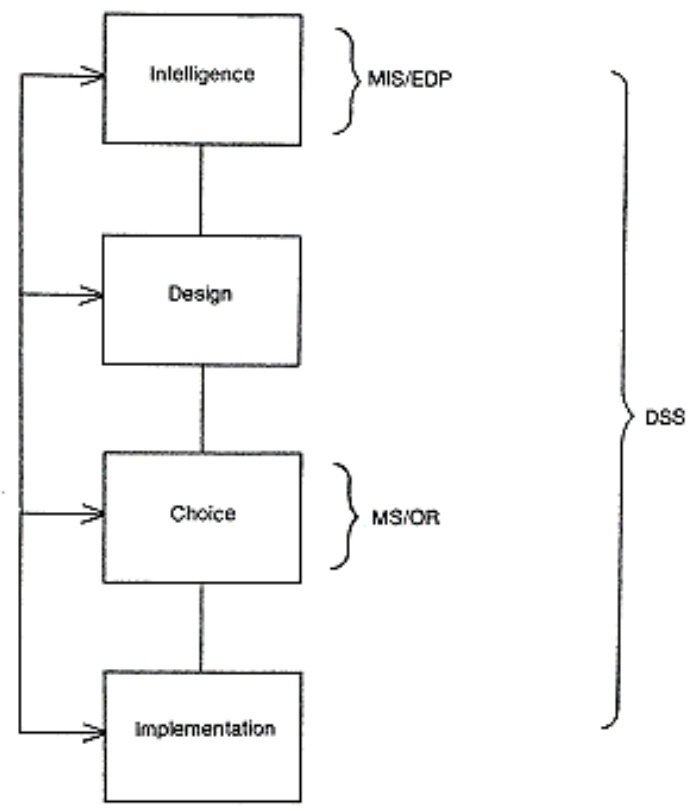

Figure 6. Phases of Decision Making and IS (Ajayi, 2007, 45)

\section{Conclusion}

The role of information in decision making cannot be overemphasized. Effective decision making demands accurate, timely and relevant information. MIS provides accurate and timely information necessary to facilitate the decision-making process and enable the organizations planning, control, and operational functions to be carried out effectively. MIS also plays the crucial 
role of providing a wide range of streamlined options from which decision-makers are able to make their preferred choices and this ensures that whatever choices are made by decision makers, the outcome, more often than not, becomes positive. This, as a matter of fact, is the reason why many decision makers tend to prefer using MIS tools when making tough business choices. MIS as renowned concept, having good decision choices guarantees viable decisions in our businesses. From the above discussion we can say that decision support system focus on decision making whereas management information system (MIS) focus on information. In Management information system it works on online mode but in decision support system it works on real time mode. The management support system supports medium level of data but in decision support system it supports huge volume of data. The management support system uses low supports of graphics but in decision support system it uses large support of graphics. The management information system focus only on fully structured task or routine for decision but decision support system focuses on structure as well as semi-structured data. Beside the above differences both MIS and DSS are core of an information system satisfying the requirement of different levels of management.

\section{References:}

1. Alvani, S.M. (2012). Public Management (Edition 23) Tehran: Nashodani.

2. Ajayi, I.A. and Omirin F.F. (2007): The use of Management Information Systems (MIS) in Decision-making in South-West Nigerian Universities.

3. Asefeh Asemi, Ali Safari, Adeleh Asemi Zavareh, the Role of Management Information System (MIS) and Decision Support System (DSS) for Manager's Decision Making Process, International J ournal of Business and Management Vol. 6, No. 7; J uly 2011.

4. Barton J ., Parolin B., Weiley V., A Spatial Decision Support System for the Management of Public Housing, in Recent Advances in Design and Decision Support Systems in Architecture and Urban Planning, Springer Science and Business Media, 2005, p. 69\&84

5. Bendoly E., Excel Basics to Blackbelt. An Accelerated Guide to Decision Support Designs, Cambridge University Press 2008

6. Bresfelean V.P., Ghisoiu N., Lacurezeanu R., Sitar\& Taut D.\&A., Towards the Development of Decision Support in Academic Environments, Proceedings of ITI 2009, Cavtat, Croatia, 2009, p. 343-348.

7. C.W. Holsapple, A.B.Whinston, Decision support systems: A knowledge-based approach, St. Paul: West Publishing, 2006.

8. Davis, Timothy; Geist, Robert; Matzko, Sarah; Westall, James (2004) a First Step". Technical Symposium on Computer Science Education, p. 125- 129.

9. Feizi, K\& Moghadassi, A. (2012). Application of Decision Support Systems (45) Management Studies in Management Decision.

10. Gabriel, J. M. O. (2013): The Systems Concept: An unpublished Lecture note giving to

B.sc Year 3 Students of Faculty of Management Sciences, Rivers State University of Science and Technology, Port Harcourt.

11. George, J. M. and Jones G. R. (1996): Understanding and managing Organizational behavior. $1^{\text {st }}$ ed., Addison-Wesley Publishing Company Inc. USA.

12. G.Satyanarayana Reddy, Rallabandi Srinivasu, Spikanth Reddy Rikkula, Vuda Sreenivasa Rao, Management information system to help managers for providing decision making in an Organization, International J ournal of Reviews in Computing, 2009. IJ RIC.

13. J aboe, K.P. (2005): Reporting intangibles: a hard look at improving business information in The U.S. Athena Alliance. Retrieved October, 2, 2010 from http://www.athenaalliance. Org/ apapers/ReportingIntangibles.htm.

14. J essup, Leonard M.; J oseph S. Valacich (2008). Information Systems Today Pearson Publishing. Pages 56 \&Glossary (3rd Ed.). p. 416.

15. Kumar, P. K. (2006): Information Systems Decision-Making, Indian MBA. Retrieved

October 2, 2010 from http:// www..indianmba.com/ Faculty column/ FC307/ fc307.html

16. Laudon, K. and J. Laudon, 2009. Management Information Systems. 11th End, Prentice

Hall, Upper Saddle River, New J ersey, ISBN: 13: 978-0136078463, pp: 627.

17. Lucey, T., 1997. Management Information Systems, London.

18. Lucey, T. (2005): Management Information Systems. London: Book Power. 
19. Manian, A. (2011). "Factors affecting the satisfaction of end users and providing satisfaction Model", $\mathrm{PhD}$ thesis, School of Management degree (Major systems), Tehran University

20. Pride W. M. And O.C. Ferrell, (2006). Marketing concepts and Strategy, $13^{\text {th }}$ end, Houghton Mifflin Company, Boston, New York.

21. Power, D.J. (2002). Decision support system: concepts and resources for managers. Westport Conn., Quorum Books.

22. Rachhpal Singh, Manik Sharma, Sandeep Sharma, Sanjeev Kumar kaushal, "Management Information System", Published by Kalyani Publishers, Edition (2012).

23. Rhodes, J. (2010): the role of Management information Systems in Decision-Making. eHow. Retrieved October 2, 2010 from http:www.eHow.com/facts 7147006 role-informationsystems Decision-making.html.

24. Vittal, A and Shivraj, K. (2008): Role of Information Technology and Knowledge Management in improving project management. 